\title{
Review Article \\ What Proportion of Terminally Ill and Dying People Require Specialist Palliative Care Services?
}

\author{
Donna M. Wilson and Boris Woytowich \\ Faculty of Nursing, University of Alberta, Edmonton, AB, Canada T6G 1C9 \\ Correspondence should be addressed to Donna M. Wilson; donna.wilson@ualberta.ca
}

Received 22 May 2014; Revised 4 September 2014; Accepted 5 September 2014; Published 11 September 2014

Academic Editor: Franco Toscani

Copyright (C) 2014 D. M. Wilson and B. Woytowich. This is an open access article distributed under the Creative Commons Attribution License, which permits unrestricted use, distribution, and reproduction in any medium, provided the original work is properly cited.

\begin{abstract}
Currently, around 55 million people die each year worldwide. That number is expected to increase rapidly with accelerating population aging. Despite growth in the number of palliative care specialists and specialist services in most countries, the prospect of an increasing number of terminally ill and dying persons is daunting. This paper attempts to answer the question: what proportion of terminally ill and dying persons require specialist palliative care services? To address this question and highlight which persons require specialist palliative care, the current state of access to specialist palliative care services and specialists in Canada and other countries is highlighted, along with available evidence-based information on specialist services utilization and the care needs of terminally ill and dying persons. Current evidence and information gaps reveal that this question cannot be answered now, but it should be answered in advance of a crisis of unmet end-of-life care needs with the rising death toll.
\end{abstract}

\section{Introduction}

Currently, 55 million people die each year worldwide [1]. Although many different illnesses and other factors are responsible for these deaths, most deaths occur in old age after advancing senescence has reduced life expectancy [1]. With population aging starting to accelerate now that the first members of the large baby boom generation have reached the age of 65 , a rapid increase in deaths is expected [2, $3]$. For instance, in 2030 , when the entire baby boom cohort has reached the age of $65,500,000$ deaths are anticipated for Canada, double the current number $[4,5]$. With most hospitals and nursing homes in Canada at full capacity now and with rising healthcare costs being a concern in Canada if not in all other countries, the prospect of an increasing number of terminally ill and dying persons is daunting. However, although some terminal illnesses (defined as the period following the diagnosis of a life-limiting illness) and some dying processes (defined as the last minutes or days of life when death is obviously imminent) are highly problematic, end-of-life care needs to vary considerably [6-10].
Needs may be minimal to extensive in number, short- to longterm in nature, and basic to complex in terms of type [610]. All people who suffer from a difficult terminal illness or dying process, such as when severe intractable pain is present, should receive the services of a palliative care medical or nurse practitioner specialist [7,9-11]. Not only are difficult symptoms or other problems more likely to be successfully addressed but also specialist palliative care services have the potential to prevent difficult symptoms and other problems from appearing or escalating in severity [7, 10-12]. The imperative to provide compassionate and effective end-of-life care, in the face of a rapidly increasing death toll, makes it critically important to answer the question: what proportion of terminally ill and dying persons require specialist palliative care services? This paper seeks to answer that question, by highlighting which terminally ill or dying persons require specialist palliative care services, the current state of access to specialist palliative care services and specialists, and available evidence-based information to distinguish specialist from generalist care needs of terminally ill and dying persons. 


\section{Materials and Methods}

A university librarian was consulted before an advanced Medline and CINAHL library database search was undertaken for English-language research articles using the keywords end-of-life/palliative care needs/utilization. Many hundreds of articles were identified, with a review of abstracts done to identify any research article that could possibly inform the question, with the full article read whenever an abstract appeared promising. As this review only revealed 32 research articles and another 23 opinion articles that had some additional relevant information, a series of Internet searches were then conducted to assess English-language palliative care association website documents for relevant facts or other information. Although most scientific reports now are in English, the search results identified below are limited since information in other languages was not incorporated.

\section{Results and Discussion}

3.1. Access to Specialist Palliative Care. Palliative care services are those designed specifically for terminally ill and dying persons, with Quill and Abernethy arguing that specialist palliative care should be reserved for more complex and difficult cases [10]. Palliative care specialists are distinct as they have obtained advanced education in the care of terminally ill and dying persons [10]. This advanced knowledge and skill set differentiates them from other nurses, physicians, and healthcare or social service professionals who have all been taught to provide basic end-of-life care in their entry-level education programs [13].

Palliative care specialist education began in the mid-1960s, when palliative care was initiated in England to promote comfort-oriented care and a higher quality of life for dying people and their families $[14,15]$. Since then, an increasing number of healthcare and other professionals have gained specialist palliative care credentials. Specialist and basic or primary palliative care services are provided in most countries now for "the prevention and relief of suffering by means of early identification and impeccable assessment and treatment of pain and other problems, physical, psychosocial and spiritual" [16, paragraph 1].

This relatively recent growth in specialists is mirrored by the relatively recent growth in palliative care services. For instance, in Canada, palliative care was initiated in 1975 when palliative care units were opened in two large hospitals [15, $17,18]$. Following this, Canadian hospitals adopted palliative care principles to facilitate the open recognition of impending death and the provision of compassionate, holistic, and patient-centered end-of-life care $[11,17]$. Today, most but not all larger hospitals in Canada have palliative care units and/or specialist teams [19], most communities have palliative homecare services, some free-standing hospices have come to exist, and a small proportion of nursing homes have dedicated palliative care beds $[20,21]$. However, specialist palliative care services remain uncommon and entirely lacking in some areas [7, 21, 22], notably small Canadian cities, towns or villages, and rural areas $[22,23]$. The scarcity of specialists and specialist services is a worldwide issue [9].
As a result of this scarcity and for other reasons, most terminal illnesses and dying processes do not involve palliative care specialists. For instance, although roughly $60 \%$ of all deaths in Canada take place in hospital [24], most endof-life care is provided by family members at home [25]. When formal homecare assistance is provided, this end-oflife care is most often delivered by unlicensed care aides [25]. Moreover, most of the care of terminally ill and dying patients in hospital is provided by healthcare workers who are not palliative care specialists [26]. Nursing homes also provide end-of-life care through their (often unlicensed) care staff $[27,28]$. In Canada, dying nursing home residents are rarely transferred to hospital for end-of-life care [29]. In 2009 [14] and again in 2012 [30], the Canadian Hospice Palliative Care Association indicated that $16 \%$ to $30 \%$ of all dying Canadians have access to palliative care.

The situation of limited access to palliative specialists and specialist services is not confined to Canada [9, 31]. Comparing access rates across countries is difficult, as comparative information is not available [32]. Access to specialist palliative care services is likely to be greater in some countries, notably England, Ireland, Wales, Scotland, and New Zealand [33-35]. These countries typically have one or more free-standing hospices in every community to provide a wide range of nonhospital specialist services [36]. These hospices typically employ one or more palliative nurses for specialized day programs and/or in-home care support [35]. Palliative nurses and other specialists are also located in hospitals in these countries, but a recent study determined that $19.8 \%$ of all patients at one large hospital in New Zealand were terminally ill or dying and almost all of these patients received their end-of-life care from generalists [37]. Some hospices in these five countries have inpatient beds, with specialist palliative care physicians typically providing services there $[35,38]$.

Specialist palliative care access may also be higher in Belgium and the Netherlands, as specialist palliative care services are developing in nursing homes for the dual purpose of ensuring high quality onsite care and reducing end-of-life transfers to hospital [39]. Access is also likely to be higher in the United States, as 3,400 hospices in 2009 were providing palliative care for 1.5 million Americans, with $41 \%$ of all Medicare decedents receiving hospice care that year [31]. Access to hospice care varies across the United States however ranging from $6.7 \%$ of potential recipients in Alaska to $44.7 \%$ of potential recipients in Arizona [31]. Community-based hospice care is particularly important as only $50 \%$ of the 2.5 million deaths each year in the United States take place in hospital and only $62 \%$ of American hospitals (those with $50+$ beds) had a palliative care program in 2006 [31]. The United States currently has around 5,000 physicians with specialist palliative care credentialing [10].

Limited specialist palliative care access in other countries is also apparent, including Asian and African countries $[9,40-43]$. For instance, only $8 \%$ of Asians in need have access to palliative specialists or specialist programs [41] and "very few" Africans receive specialist palliative care [42]. The African Palliative Care Association [43] estimated that 9.7 million people each year in Africa have end-of-life care needs, with another African report indicating that less than $1 \%$ of 
children in Kenya and less than 5\% of children in South Africa or Zimbabwe in need of palliative care have access to it [44].

Access to specialized services is dependent upon specialists. The first major initiative in palliative specialist education occurred in the United Kingdom (UK) in the 1970s, with Macmillan nurses [45] and Marie Curie nurses [46] subsequently active in many UK communities [47]. The UK also led in medical palliative education programs [47]. Many other countries followed suit, but it was not until the 1997 Institute of Medicine report, Approaching Death: Improving Care at the End of Life, documented "glaring deficiencies in end-oflife care in the United States" [48, paragraph 4] that largescale palliative care specialization and program expansion occurred in the United States. By 2006, there were 57 US palliative medicine fellowship programs, and both the American Board of Medical Specialties and Accreditation Council for Graduate Medical Education recognized hospice/palliative medicine as a subspecialty [48]. Most other developed countries have also initiated palliative education programs and formal recognition measures [9, 31, 49]. For instance, in July 2013, 1,487 Canadian nurses had gained palliative specialty credentialing [50]. Medical specialist expansion is anticipated now with new two-year subspecialist programs and other efforts to ensure that a growing proportion of Canadian physicians gain palliative specialist knowledge and skills $[51,52]$. In contrast, few lower-income countries have specialist palliative training programs of any kind $[9,32]$. Consequently, palliative specialists are limited in number worldwide, with this scarcity of specialists being a concern now and for the future with an increasing number of deaths. Not only do specialists provide direct care but also they plan palliative care services and educate generalists to enable them to provide effective basic or primary end-of-life care [10].

3.2. Need for Specialist Palliative Care. It could be argued that all terminally ill and dying persons should have ready palliative care access $[14,30]$. However, some people do not accept palliative care when it is presented as a care option, and it should not be forced on them [53]. Moreover, roughly $10 \%$ of deaths occur quickly and unexpectedly $[1,38,54]$, with palliative care not possible or necessary in these cases [7]. Most often an end-of-life process of some duration occurs, over which there may be a need for periodic or ongoing specialist palliative care [55]. Unfortunately, few research articles differentiate the care needs of terminally ill or dying persons to suggest when or if specialist palliative care is required.

The available research indicates that all people are completely disabled in the last few minutes, hours, or days of life $[8,56]$. Care needs at this time are often basic, as the person is bedridden and comatose or semicomatose $[8,26,56]$. Repositioning or turning, mouth care, quiet reassurance, and basic hygiene measures are often only required at this time [8]. These basic care needs can be met by family members and by healthcare providers who are not palliative care specialists [7]. At this point in time, technologies are commonly but controversially used as comfort measures [8]. One recent study showed that $97.3 \%$ of all 1,018 decedents in a Canadian hospital had one or more life-sustaining technologies (typically oxygen and an intravenous infusion) in use at the time of death [26]. In most cases, these technologies were in use prior to the last days of life and they were not withdrawn from use despite some indications that they were no longer necessary or useful [26]. Palliative care specialists are not required to order their use or use discontinuation.

Prior to the final stage of life near death, care needs are much more varied. One study found that only a small proportion of people are very disabled at the time they are diagnosed as terminally ill [26]. Terminal illnesses can be lengthy, lasting for weeks, months, or even years [11]. Chief among all possible care needs from the time of a terminal diagnosis to death are emotional, spiritual, and other psychosocial needs $[7,57,58]$. The intensity and range of these psychosocial needs are influenced by the person's culture, gender, age, family, and many other factors [57]. The goal is for all dying persons to achieve peaceful and painless death after having lived as fully as possible, with dying persons and their families prepared for death [16]. This goal is difficult to achieve when psychosocial needs are high and personal or family resources are low. In these cases, palliative specialist or other specialist (i.e., psychiatric or psychological) care is indicated. This goal may also not be met if the dying process progresses rapidly or if severe pain and other symptoms are present $[9,57]$. In these cases, terminal or palliative sedation may be indicated, with this sedation typically provided by palliative care specialists [7]. Regardless, it is clear that most of the psychosocial and physical care needs of terminally ill and at times dying persons are met by family members and/or friends [57]. These needs may also be periodically met by family physicians and nurses in clinics or hospitals [59]. Empathy, caring, and respect for the dying person and their family are important, all of which do not require specialist preparation [57].

Care coordination or case management is another common and important end-of-life care need [55]. Most often, this need is met by family members or friends [7]. Formal case managers are needed if family members are not present or are unable to coordinate care [55]. Most case managers are not specialists in palliative care [22].

Physical care needs are also common during terminal illnesses, with these needs typically increasing in number and intensity over time [56]. Increased fatigue and weakness are common, along with a growing dependency on others as a result of this decline in physical strength [56]. Lack of appetite, constipation, incontinence, mild confusion, skin care needs, and other physical care needs often arise during terminal illnesses [56]. These needs tend to vary across individuals, often in keeping with the specific disease [9] and any comorbidities causing disability or death [55]. For instance, pain care needs are common with cancer. With respiratory illnesses, shortness of breath and hypoxic restlessness are common and these often create substantial care needs [60]. With cardiovascular illnesses, care needs arising from peripheral edema and/or pulmonary edema are common [60]. All symptoms are very important to address, in part because severe and difficult-to-manage symptoms often result in hospitalizations 
$[19,26]$. It is also important to note that physical care needs result from diagnostic tests and treatments. Incision care needs with surgery, nausea prevention and management needs with chemotherapy, and skin care needs with radiation illustrate additional care needs that should be foregone if the tests or treatments are unnecessary.

Unless sudden death occurs, terminally ill people often experience a pattern of first needing some assistance to stand up and walk, with this progressing to needing two-person assistance to walk, before deathbed care is required [8]. Most physical care needs during a terminal illness can be addressed by family caregivers, often with information and/or assistance from generalist healthcare professionals [6]. Only a small proportion of people (typically only the $4-8 \%$ who require nursing home-level care) have extensive physical care needs for a number of months or even years before death [27, 28]. One study found that $80 \%$ of people were still able to walk, alone or with assistance, three days before death [8]. Depending on the care needs, specialist palliative care may be indicated periodically, not at all, or over an entire terminal illness. The Worldwide Palliative Care Alliance's recent report indicates that 20 million people or $37.4 \%$ of the 55 million people who die worldwide each year need palliative care, with this estimation based on disease-specific cause-of-death counts and expert opinion consolidated through a Delphi process [9].

Unless otherwise indicated, care during a terminal illness is typically provided in the person's home or nursing home residence and without specialist palliative care involvement $[36,38,61]$. For instance, most people with advanced chronic obstructive lung disease live at home despite periodic breathing crises that require attention in hospital emergency departments or medical offices [62]. Other persons, such as the frail elderly who are approaching death, may also not require specialist palliative care assessment or intervention services [5]. One large study found that $29.3 \%$ of all deaths in western Canada were due primarily to advanced old age [6]. Similarly, people with advanced dementia constitute another group that may be more in need of basic supportive care than specialist palliative care $[61,63]$.

Assessment tools to demonstrate clinical and other criteria that indicate a need for periodic or ongoing specialist palliative care have been an important development in the quest to determine which individuals require specialist services. The Gold Standards Framework [12] and the Liverpool Care Pathway are among the most well-known and commonly used tools [64]. These tools were designed to help ensure that quality of end-of-life care occurs in any care location, by anticipating or predicting care needs. These and other tools also assist in identifying dying persons with specialist palliative care needs $[10,12]$.

Another way of determining the extent of need for specialist palliative care is through determining which terminally ill or dying persons have received specialist palliative care services. Palliative care clients in most countries have been those who are dying from cancer [19, 65]; for instance, $95 \%$ of recent recipients of specialist hospice/palliative care in the UK had end-stage cancer [66]. However, people suffering from end-stage neurological, cardiovascular, and lung diseases are increasingly receiving specialist palliative care services [66], as these diseases cause significant physical and psychological distress $[67,68]$. Another access factor appears to be age; recipients of specialist palliative care services have tended to be under the age of $65[11,69,70]$. In Canada, younger people diagnosed with incurable cancer are much more often referred for specialist palliative care than older persons [11]. This age factor is understandable since younger dying persons and their families often have a higher psychological burden [68]. These age- and disease-based rationing strategies may be successful at ensuring that the neediest persons receive specialist palliative care, but research is needed to validate these strategies and more clearly identify which persons should receive specialist palliative care services.

3.3. Arguments for or against an Expansion of Specialist Palliative Care. Many arguments have been made for specialist palliative care expansion. For instance, expansion was first recommended in Canada in 1995 when limited access to it was evident and with expansion argued to prevent requests for assisted suicide or euthanasia [17]. Expansion in specialist palliative care experts and services subsequently occurred [11]. In 2002, the Canadian Strategy on Palliative and Endof-Life Care was established to continue expanding specialist palliative and basic end-of-life care services. The Canadian Hospice Palliative Care Association's 2009 [14] expansion strategy also encouraged new palliative care services across Canada, as did a third Senate of Canada [7] report. Other countries similarly have had an expansion of specialist palliative care experts, programs, and services; and an increase in educational offerings aimed at ensuring that family physicians and others know when specialist care is indicated [7173].

However, specialist palliative care expansion is not without controversy. Some fear medicalizing a normal life process, just as birthing became a medicalized and hospitalized process [74]. Others fear burdening terminally ill and dying people with a change in healthcare providers [10], with more travelling required to obtain specialist services [75]. The higher cost of specialists over generalists is another consideration $[10,55]$, with this higher cost potentially reducing the availability of basic end-of-life care, such as homecare services or respite for family caregivers. However, there may be much added value from palliative care specialists and specialist services, as was indicated in an assessment of the quality of dying in 40 countries [32]. The countries where specialist palliative care is well established were typically rated as having high quality dying. Regardless, more efforts are needed to track specialist education developments, such as the helpful IAHPC Global Directory of Education in Palliative Care [76]. More efforts are also needed to track palliative care services and care outcomes, such as the second comprehensive report on palliative care services in Australia [73]. More efforts are also needed to advocate for palliative research funding and for widely disseminated research findings, as is being done through the European Association for Palliative Care [77]. 


\section{Conclusion}

The majority of terminally ill and dying persons currently pass away with limited if any access to palliative care specialists and specialist services. Although there may be many benefits of specialist palliative care not only to the recipients but also to their family and society as a whole, it is not clearly evident at this point in time what proportion of terminally ill and dying persons require specialist palliative care. The focus in recent decades has been on expanding specialist providers and services to increase access to specialist palliative care. Research is needed now to determine which persons and/or which circumstances necessitate specialist palliative care. This research is critical for ensuring that a good death can occur in every care setting.

\section{Conflict of Interests}

The authors have no conflict of interests to declare.

\section{References}

[1] World Health Organization, "The Top Ten Causes of Death," 2013, http://www.who.int/mediacentre/factsheets/fs310/en/ index $2 . h t m l$.

[2] Index Mundi, Canada Death Rate. Demographics: Death Rate 2011, http://www.indexmundi.com/g/g.aspx? $\mathrm{c}=\mathrm{ca} \& \mathrm{v}=26$.

[3] S. T. Simon, B. Gomes, P. Koeskeroglu, I. J. Higginson, and C. Bausewein, "Population, mortality and place of death in Germany (1950-2050)-Implications for end-of-life care in the future," Public Health, vol. 126, no. 11, pp. 937-946, 2012.

[4] Statistics Canada, "Leading causes of death in Canada," Catalogue number 84-215-XWE, 2011, http://www.statcan.gc.ca/ bsolc/olc-cel/olc-cel?catno=84-215-x\&lang=eng\&lang=eng.

[5] D. M. Wilson, J. Cohen, S. Birch et al., "No one dies of old age': implications for research, practice, and policy," Journal of Palliative Care, vol. 27, no. 2, pp. 148-156, 2011.

[6] Canadian Institute for Health Information, Health Care Use at the End of Life in Western Canada, 2007, http://secure.cihi.ca/ cihiweb/products/end_of_life_report_aug07_e.pdf.

[7] Senate of Canada, "Raising the Bar: A Roadmap for the Future of Palliative Care in Canada 2010," http://www.chpca.net/media/ 7859/Raising_the_Bar_June_2010.pdf.

[8] D. M. Wilson, "The duration and degree of end-of-life dependency of home care clients and hospital inpatients," Applied Nursing Research, vol. 15, no. 2, pp. 81-86, 2002.

[9] World Palliative Care Alliance, "Global Atlas of Palliative Care at the End of Life," 2014, http://www.thewpca.org/resources/ global-atlas-of-palliative-care/.

[10] T. E. Quill and A. P. Abernethy, "Generalist plus specialist palliative care-creating a more sustainable model," The New England Journal of Medicine, vol. 368, no. 13, pp. 1173-1175, 2013.

[11] Senate of Canada, Subcommittee of the Standing Senate Committee on Social Affairs, Science, and Technology, Quality Endof-Life Care: The Right of Every Canadian, The Senate of Canada, Ottawa, Canada, 2000, http://www.parl.gc.ca/36/2/parlbus/ commbus/senate/Com-e/upda-e/rep-e/repfinjun00-e.htm.

[12] Royal College of General Practitioners, "The Gold Standards Framework," Prognostic Indicator Guidance, 2008, http://www .gpscbc.ca/system/files/11_EOL_PSP_GSF_Prognostic_Indicator_ $0 . p d f$.
[13] D. M. Wilson, B. Goodwin, and J. A. Hewitt, "An examination of palliative or end-of-life care education in introductory nursing programs across Canada," Nursing Research and Practice, vol. 2011, Article ID 907172, 5 pages, 2011.

[14] Canadian Hospice Palliative Care Association, "Caring for Cana-di-ans at End of Life. A Strategic Plan for Hospice, Palliative and End-of-life Care in Canada to 2015," 2009, http://www .chpca.net/uploads/files/english/about_us/CHPCA_Strategic Plan.pdf.

[15] E. Klaschik and F. Nauck, "History of palliative medicine," Zentralblatt für Chirurgie, vol. 123, no. 6, pp. 620-623, 1998.

[16] World Health Organization, WHO Definition of Palliative Care, World Health Organization, Geneva, Switzerland, 2012, http:// www.who.int/cancer/palliative/definition/en/.

[17] Senate of Canada-Special Senate Committee on Euthanasia and Assisted Suicide, "Of Life and Death," Final Report, 1995, http://www.parl.gc.ca/Content/SEN/Committee/351/euth/rep/ lad-tc-e.htm.

[18] Victoria Hospice, History of Palliative Care, 2011, http://www .victoriahospice.org/about/history-victoria-hospice.

[19] J. Cohen, D. M. Wilson, A. Thurston, R. MacLeod, and L. Deliens, "Access to palliative care services in hospital: a matter of being in the right hospital. Hospital charts study in a Canadian city," Palliative Medicine, vol. 26, no. 1, pp. 89-94, 2012.

[20] Cancer Care Ontario, Regional Models of Care for Palliative Cancer Care: Recommendations for the Organization and Delivery of Palliative Cancer Care in Ontario, Cancer Care Ontario, Ontario, Canada, 2009, https://www.cancercare.on.ca/common/ pages/UserFile.aspx?fileId=77326.

[21] A. M. Williams, V. A. Crooks, K. Whitfield et al., "Tracking the evolution of hospice palliative care in Canada: a comparative case study analysis of seven provinces," BMC Health Services Research, vol. 10, article 147, 2010.

[22] Parliamentary Committee on Palliative and Compassionate Care, "Not to be forgotten. Care of Vulnerable Canadians," 2011, http://pcpcc-cpspsc.com/wp-content/uploads/2011/11/ReportEN .pdf.

[23] W. D. Duggleby, K. Penz, B. D. Leipert, D. M. Wilson, D. Goodridge, and A. Williams, "'I am part of the community but...' The changing context of rural living for persons with advanced cancer and their families," Rural and Remote Health, vol. 11, no. 3, article 1733, 2011.

[24] D. M. Wilson, C. D. Truman, R. Thomas et al., "The rapidly changing location of death in Canada, 1994-2004," Social Science and Medicine, vol. 68, no. 10, pp. 1752-1758, 2009.

[25] D. M. Wilson, C. Truman, J. Huang et al., "Home care evolution in Alberta: how have palliative clients fared?" Healthcare Policy, vol. 2, no. 4, pp. 44-56, 2007.

[26] A. Thurston, D. M. Wilson, and J. A. Hewitt, "Current end-oflife care needs and care practices in acute care hospitals," Nursing Research and Practice, vol. 2011, Article ID 869302, 8 pages, 2011.

[27] D. Wilson and C. Truman, "Long-term-care residents. Concerns identified by population and care trends," Canadian Journal of Public Health, vol. 95, no. 5, pp. 382-386, 2004.

[28] D. Wilson and C. Truman, "Comparing the health services utilization of long-term-care residents, home-care recipients, and the well elderly," Canadian Journal of Nursing Research, vol. 37, no. 4, pp. 138-154, 2005.

[29] B. Cable-Williams and D. Wilson, "Awareness of impending death for residents of long-term care facilities," International Journal of Older People Nursing, vol. 9, no. 2, pp. 169-179, 2014. 
[30] Canadian Hospice Palliative Care Association, "Fact sheet: Hospice palliative care in Canada," 2012, http://www.chpca.net/ media/7622/fact_sheet_hpc_in_canada_may_2012_final.pdf.

[31] D. E. Meier, "Increased access to palliative care and hospice services: opportunities to improve value in health care," Milbank Quarterly, vol. 89, no. 3, pp. 343-380, 2011.

[32] Economist Intelligence Unit, The quality of death, Ranking end-of-life care across the world, 2010, http://graphics.eiu.com/ upload/QOD_main_final_edition_Jul12_toprint.pdf.

[33] C. Centeno, D. Clark, T. Lynch et al., "Facts and indicators on palliative care development in 52 countries of the WHO European region: results of an EAPC task force," Palliative Medicine, vol. 21, no. 6, pp. 463-471, 2007.

[34] D. Clark and C. Centeno, "Palliative care in Europe: an emerging approach to comparative analysis," Clinical Medicine, Journal of the Royal College of Physicians of London, vol. 6, no. 2, pp. 197-201, 2006.

[35] Hospice New Zealand, What is hospice?, 2006, http://www .hospice.org.nz/.

[36] D. M. Wilson, S. Birch, S. Sheps, R. Thomas, C. Justice, and R. MacLeod, "Researching a best-practice end-of-life care model for Canada," Canadian Journal on Aging, vol. 27, no. 4, pp. 319$330,2008$.

[37] M. Gott, R. Frey, D. Raphael, A. O'Callaghan, J. Robinson, and M. Boyd, "Palliative care need and management in the acute hospital setting: a census of one New Zealand Hospital," BMC Palliative Care, vol. 12, no. 1, article 15, 2013.

[38] Department of Health, End of Life Care Strategy, National Health Service, 2008, http://www.dh.gov.uk/en/Publicationsandstatistics/Publications/PublicationsPolicyAndGuidance/ DH_086277.

[39] D. Houttekier, J. Cohen, J. Surkyn, and L. Deliens, "Study of recent and future trends in place of death in Belgium using death certificate data: a shift from hospitals to care homes," $B M C$ Public Health, vol. 11, article 228, 2011.

[40] D. Clark, M. Wright, J. Hunt, and T. Lynch, "Hospice and palliative care development in Africa: a multi-method review of services and experiences," Journal of Pain and Symptom Management, vol. 33, no. 6, pp. 698-710, 2007.

[41] K. Breaden, "Teaching palliative care across cultures: the singapore experience," Indian Journal of Palliative Care, vol. 17, no. 4, pp. S23-S25, 2011.

[42] R. A. Powell, F. N. Mwangi-Powell, F. Kiyange et al., "Palliative care development in Africa: how can we provide enough palliative care?" BMJ Supportive and Palliative Care, vol. 1, no. 2, pp. 113-116, 2011.

[43] African Palliative Care Association, "Palliative Care in Africa: The Need," 2013, http://www.africanpalliativecare.org/index .php?option=com_content\&amp; view=article.

[44] S. R. Connor and C. Sisimayi, Assessment of the Need for Palliative Care for Children. Three Country Report: South Africa, Kenya and Zimbabwe, 2013, http://www.unicef.org/search/search.php? $\mathrm{q}=$ Assessment + of + the + Need + for + Palliative + Care + for + Children \&Go.x=13\&Go.y=10.

[45] Macmillan Cancer Support, Home Page, 2011, http://www .macmillan.org.uk/Home.aspx.

[46] Marie Curie Cancer Care, How we Started, 2011, http://www .mariecurie.org.uk/en-gb/who-we-are/how-we-started.

[47] D. Clark, Hospice in Historical Perspective. Encyclopedia of Death and Dying, 2012, http://www.deathreference.com/Ho$\mathrm{Ka} /$ Hospice-in-Historical-Perspective.html.
[48] M. J. Loscalzo, "Palliative care: an historical perspective," Hematology/the Education Program of the American Society of Hematology, vol. 1, p. 465, 2008.

[49] H. D. Berman, "Palliative care is a specialty," Canadian Family Physician, vol. 54, no. 11, p. 1526, 2008.

[50] Canadian Nurses Association, Number of Valid CNA Certifications by Specialty Area of Nursing Practice and Province or Territory, 2013, http://www.nurseone.ca/docs/NurseOne/Certification/Certification_stats_2013_e.pdf.

[51] Canadian Institute for Health Information, Number of Doctors in Canada Rising, as Are Payments for Their Services, Canadian Institute for Health Information, 2013, http://www.cihi.ca/cihiext-portal/internet/en/document/spending+and+health+workforce/workforce/physicians/release_26sep13.

[52] M. Monette, "Palliative care subspecialty in the offing," Canadian Medical Association Journal, vol. 184, no. 12, pp. E653E654, 2012.

[53] S. N. Davison, "End-of-life care preferences and needs: Perceptions of patients with chronic kidney disease," Clinical Journal of the American Society of Nephrology, vol. 5, no. 2, pp. 195-204, 2010.

[54] British Columbia Ministry of Health, "A Provincial Framework for End-of-life Care," 2006, http://www.health.gov.bc.ca/ hcc/endoflife.html.

[55] T. W. LeBlanc, D. C. Currow, and A. P. Abernethy, "On Goldilocks, care coordination, and palliative care: making it “just right"', Primary Care Respiratory Journal, vol. 23, no. 1, pp. 8-10, 2014.

[56] M. Harlos, When Death is Near. Physical Changes in Dying. Canadian Virtual Hospice, 2011, http://www.virtualhospice.ca/ en_US/Main+Site+Navigation/Home/Topics/Topics/Final+Days/ When+Death+Is+Near.aspx.

[57] R. D. MacLeod, "Setting the context-what do we mean by psychosocial care in palliative care?" in Psychosocial Issues in Palliative Care, M. Lloyd Williams, Ed., chapter 1, pp. 1-20, Oxford University Press, Oxford, UK, 2nd edition, 2008.

[58] S. Shah, M. Blanchard, A. Tookman, L. Jones, R. Blizard, and M. King, "Estimating needs in life threatening illness: a feasibility study to assess the views of patients and doctors," Palliative Medicine, vol. 20, no. 3, pp. 205-210, 2006.

[59] M. D. Wenrich, J. R. Curtis, D. A. Ambrozy, J. D. Carline, S. E. Shannon, and P. G. Ramsey, "Dying patients' need for emotional support and personalized care from physicians: perspectives of patients with terminal illness, families, and health care providers," Journal of Pain and Symptom Management, vol. 25, no. 3, pp. 236-246, 2003.

[60] M. J. Johnson and S. Booth, "Palliative and end-of-life care for patients with chronic heart failure and chronic lung disease," Clinical Medicine, Journal of the Royal College of Physicians of London, vol. 10, no. 3, pp. 286-289, 2010.

[61] K. A. Froggatt, D. M. Wilson, C. Justice et al., "End-of-life care in long-term care settings for older people: a literature review," International Journal of Older People Nursing, vol. 1, pp. 45-50, 2006.

[62] D. M. Wilson, C. Ross, D. Goodridge, P. Davis, A. Landreville, and K. Roebuck, "The care needs of community-dwelling seniors suffering from advanced chronic obstructive pulmonary disease," Canadian Journal on Aging, vol. 27, no. 4, pp. 347$357,2008$.

[63] I. Barnes, "End-of-life care for residents with dementia," Canadian Nursing Home, pp. 54-59, 2005. 
[64] K. Chinthapalli, "The birth and death of the Liverpool care pathway," British Medical Journal, vol. 347, no. 7918, Article ID f4669, 2013.

[65] M. Costantini, V. Romoli, S. de Leo et al., "Liverpool Care Pathway for patients with cancer in hospital: a cluster randomised trial," The Lancet, vol. 383, no. 9913, pp. 226-237, 2014.

[66] Palliative Care, 2013, http://www.patient.co.uk/doctor/palliative-care.

[67] P. Edmonds, S. Karlsen, S. Khan, and J. Addington-Hall, "A comparison of the palliative care needs of patients dying from chronic respiratory diseases and lung cancer," Palliative Medicine, vol. 15, no. 4, pp. 287-295, 2001.

[68] G. Johnston, B. G. Lawson, J. Gao et al., "Predictors of palliative care program enrollment in Nova Scotia, Canada using new analytic methods for improved application and understanding," Palliative Medicine, vol. 22, no. 4, p. 418, 2008.

[69] F. Burge, B. Lawson, and G. Johnston, "Trends in the place of death of cancer patients, 1992-1997," Canadian Medical Association Journal, vol. 168, no. 3, pp. 265-270, 2003.

[70] F. I. Burge, B. J. Lawson, G. M. Johnston, and E. Grunfeld, "A population-based study of age inequalities in access to palliative care among cancer patients," Medical Care, vol. 46, no. 12, pp. 1203-1211, 2008.

[71] S. J. J. Claessen, A. L. Francke, Y. Engels, and L. Deliens, "How do GPs identify a need for palliative care in their patients? An interview study," BMC Family Practice, vol. 14, article 42, 2013.

[72] C. Gardiner, M. Gott, C. Ingleton et al., "Extent of palliative care need in the acute hospital setting: a survey of two acute hospitals in the UK," Palliative Medicine, vol. 27, no. 1, pp. 76-83, 2013.

[73] Australian Institute of Health and Welfare, Palliative Care Services in Australia 2013, 2013, http://www.aihw.gov.au/WorkArea/DownloadAsset.aspx?id=60129545131.

[74] R. Johanson, M. Newburn, and A. Macfarlane, "Has the medicalisation of childbirth gone too far?" British Medical Journal, vol. 324, no. 7342, pp. 892-895, 2002.

[75] D. M. Wilson, L. Fillion, R. Thomas, C. Justice, P. P. Bhardwaj, and A.-M. Veillette, "The "good" rural death: a report of an ethnographic study in Alberta, Canada," Journal of Palliative Care, vol. 25, no. 1, pp. 21-29, 2009.

[76] International Association of Hospice \& Palliative Care, IAHPC Global Directory of Education in Palliative Care, 2014, http:// hospicecare.com/global-palliative-care/global-directory-of-education-programs/results.php?idregion $=0$ \&idlanguage $=1 \&$ search $=$ Search.

[77] European Association for Palliative Care, Welcome to the EAPC Research Network, 2014, http://www.eapcnet.eu/Themes/Research/ AbouttheEAPCResearchNetwork/tabid/678/Default.aspx. 


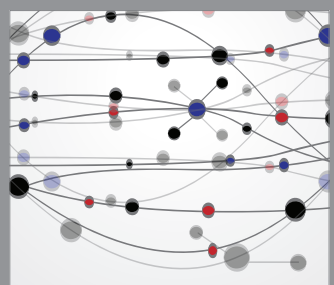

The Scientific World Journal
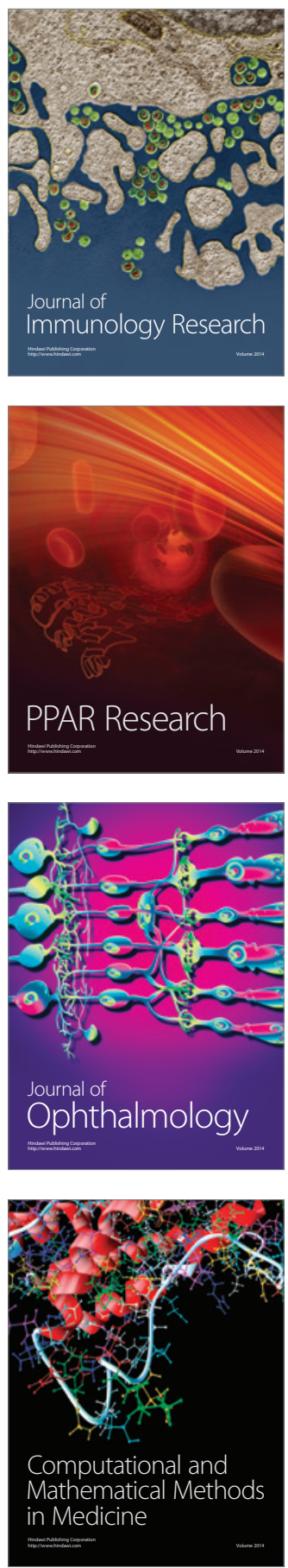

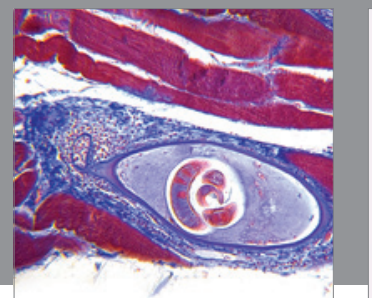

Gastroenterology

Research and Practice
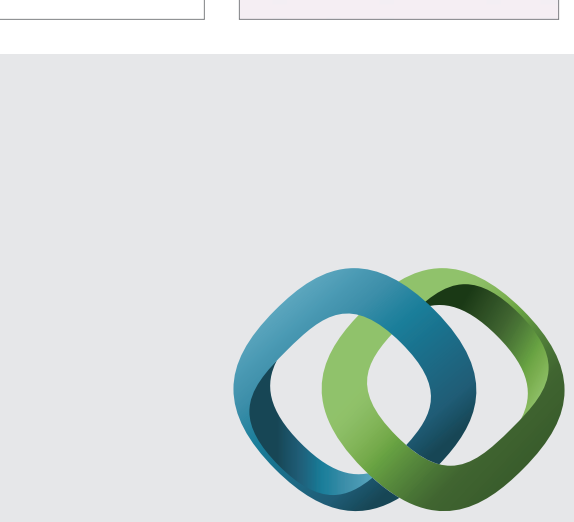

\section{Hindawi}

Submit your manuscripts at

http://www.hindawi.com
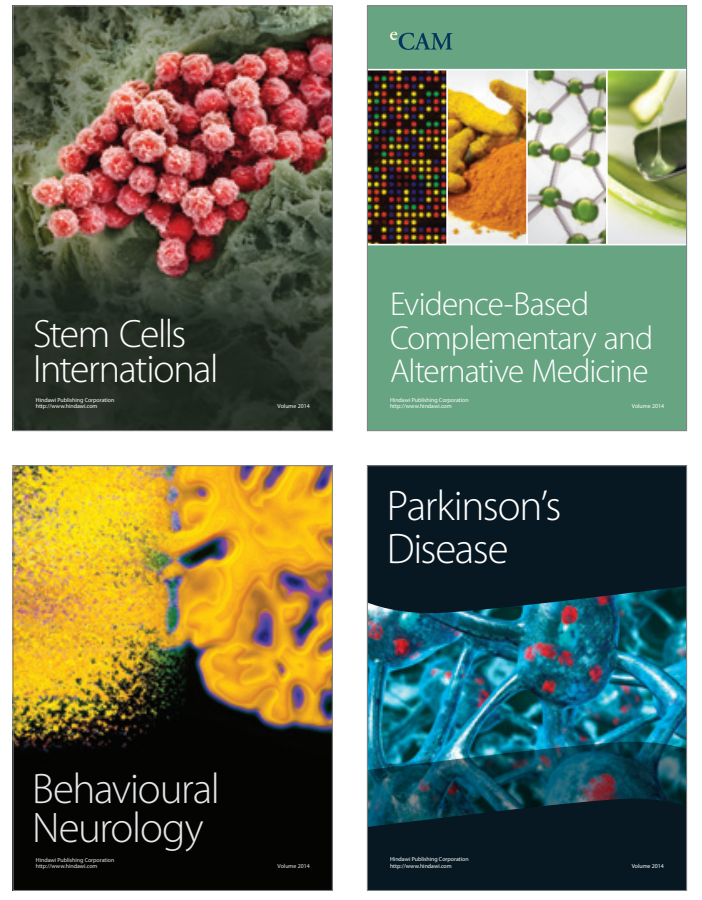
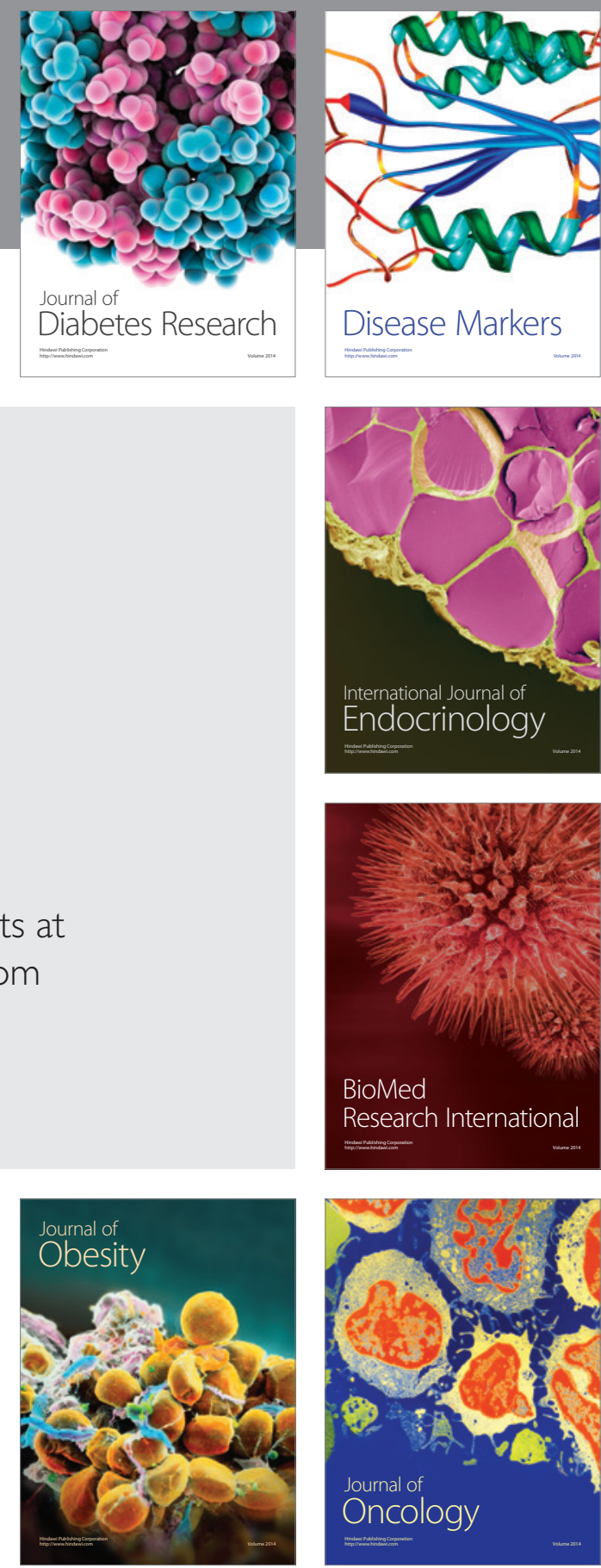

Disease Markers
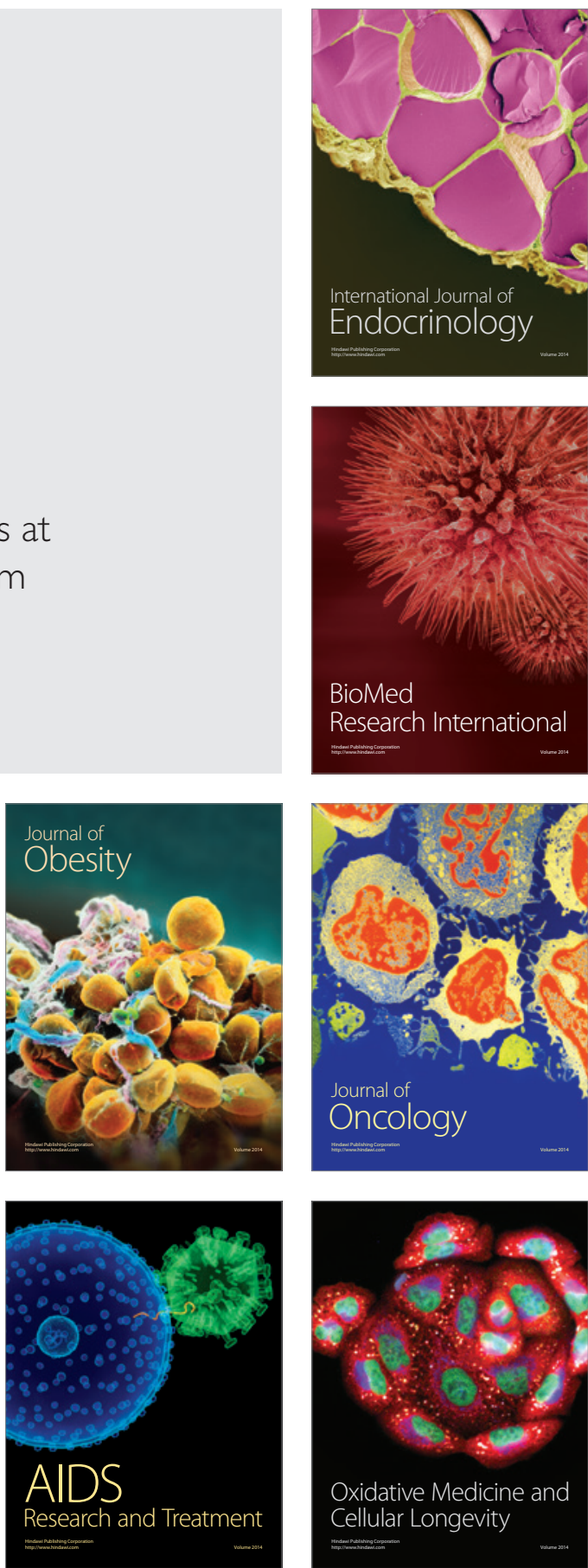